\title{
Counseling Practice and its Effectiveness (The Case of Amanuel Mental Health Specialized Hospital and Jimma University Teaching Hospital)
}

\author{
Amanuel Tadesse Koya \\ Lecturer in Gambella University, Ethiopia
}

\begin{abstract}
Counselors play a critical role in helping people who are experiencing mental or emotional problems to get their lives back on track. And it is one of the treatment options for mentally ill peoples for its deal with wellness, personal growth, and career, education, and empowerment concerns. The purpose of the study is to assess the practice of counseling and its effectiveness in Jimma University Teaching Hospital (JUTH) and Amanuel Mental Health Specialized Hospital (AMHSH). It guided by mixed research design, quantitative and qualitative data about study variables was collected from 123 patients from both institutions, Qualitative data were analyzed by direct quotation according to the theme of the questions. Descriptive percentage and ANOVA analysis were used to analyze quantitative data. Descriptive statistics showed that there is a difference in the applications of counseling within the institution Analysis of ANOVA showed counseling is more effective in the treatment of depression and substance abuse. The difference in counseling provision in both institutions is also supported by qualitative analysis of the data. So, JUTH has to incorporate counseling service in the part of treatment, and AMUSH has to work on addressing a huge number of in need patients by expanding the institution.
\end{abstract}

Keywords: Counseling; Effectiveness; Mental illness.

(c) () CC BY: Creative Commons Attribution License 4.0

\section{Introduction}

Counseling, in different forms and with different interpretations, has existed in societies for a long time. Counseling has now become institutionalized. The differences and contradictions in present-day counseling have their origin in the social and historical forces that have shaped modern culture. People in all societies, and at all times, have experienced emotional or psychological distress and behavioral problems. In each culture, there have been well-established ways and methods of helping individuals with their problems (UNESCO).

Counseling deals with wellness, personal growth, career, education, and empowerment concerns. In other words, counselors work in areas that involve a plethora of issues including those that are personal and those that are interpersonal. These areas include concerns related to finding meaning, adjustment, and fulfillment in mental and physical health and the achievement of goals in such settings as work and school. Counselors are concerned with social justice and advocate for the oppressed and powerless as a part of the process. The use of counseling as a way of responding to people in distress has grown rapidly in recent years. While it has proven popular with many people, the rapid growth of counseling has also generated some disquiet and numerous questions (Feltham, 1999).

Mental illness is considered a silent epidemic throughout most parts of Africa. Owing to structural and systemic barriers such as inadequate health care infrastructure, insufficient number of mental health specialists, and lack of access to all levels of care, (Becker and Kleinman, 2013; Collins et al., 2011) mental illness has been characterized as a neglected and increasingly burdensome problem affecting all segments of the population throughout Africa. Prioritizing mental health has also been difficult due to lack of resources, limited funding and no or ineffective mental health policies. Furthermore, a considerable segment of the population in African countries is vulnerable to mental illness due to psychosocial and socioeconomic stressors such as poverty, migration, war, conflict, and disasters (Okasha, 2002).

Amanuel Mental Health Specialized Hospital is the only hospital that is established for mental ill peoples. Since counseling is one dimension for treatment of the disorders this study is intended on their practical trends of counseling, the effectiveness of counseling they are providing and how professionals of these institutions perceive toward counseling.

Jimma University Teaching Hospital (JUTH) is found in Jimma town, Oromia regional state, southwest Ethiopia. It is $352 \mathrm{~km}$ southwest of Addis Ababa, the capital city of Ethiopia. The department of psychiatry under JUSH was established in 1988 next to Amanuel Specialized mental hospital in the country. Currently, there are about 5405 follow up outpatients and the clinic officially has 26 beds for inpatient services.

\subsection{Statement of the Problem}

Based on the results of extensive research on the effects of psychological treatments, the American Psychological Association (APA) recently passed a resolution recognizing the substantial clinical impact of counseling (America Psychological Association, 2013). Although a global statement about the positive effect of psychotherapy does reflect the general research findings, it provides little guidance on the important nuances that abound in the psychological treatment literature. Counseling has been developed to address a broad range of mental 
health and health conditions, which makes awareness of these nuances key to understanding the strength of research findings pertinent to a specific disorder or condition. Such information is essential for clinicians delivering psychological treatments, for those developing policies on first-line treatment options, and, of course, for those seeking treatment.

Qualitative research by Berhanu and Solomon (2014), was revealed that trends and factor of mental illness in JUTH. But the recent study will assess the counseling services of Amanuel Mental Health Specialized Hospital and Jimma University Teaching Hospital.

\subsection{Research Questions}

1. How counseling is applied in Jimma University Teaching Hospital and Amanuel Mental Health Specialized Hospital in treating their clients?

2. To what extent counseling services are effective for their clients?

3. For what disorder counseling is more effective?

\subsection{Objective}

\subsubsection{General Objective}

The study will assess the practice of counseling, its effectiveness, and perceptions of mental health professionals towards counseling at Jimma University Teaching Hospital and Amanuel Mental Health Specialized Hospital.

\subsubsection{Specific Objectives}

1. To examine the counseling practice of Jimma University Teaching Hospital and Amanuel Mental Health Specialized Hospital.

2. To explore counseling effectiveness of both institutions serving their client.

3. To explore which disorder counseling is an effective treatment.

\section{Reviews of Related Literature}

\subsection{Counseling and Guidance}

The term counseling has eluded definition for years. However, in 2010, 29 counseling associations including the American Counseling Association (ACA) and all but two of its 19 divisions, along with the American Association of State Counseling Boards (AASCB), the Council for the Accreditation of Counseling and Related Educational Programs (CACREP), the National Board for Certified Counselors (NBCC), the Council of Rehabilitation Education (CORE), the Commission of Rehabilitation Counselor Certification (CRCC), and the Chi Sigma Iota (counseling honor society international) accepted a consensus definition of counseling.

According to the 20/20: A Vision for the Future of Counseling group, counseling is defined as follows: "Counseling is a professional relationship that empowers diverse individuals, families, and groups to accomplish mental health, wellness, education, and career goals" (www .counseling.org/20-20/index.aspx). This definition contains a number of implicit and explicit points that are important for counselors as well as consumers to realize.

\subsection{Counseling and Guidance in Africa}

The leading Kenyan author Doh (2009) has sage, ironic advice for those who attempt such hubris and we have sought to avoid falling into too many of the traps and clichés he has pointed out, such as treating the continent as if it were one place or avoiding descriptive precision. Here we have sought to be specific, deliberately precise and to eschew the stereotypes so prevalent in some Western writings that play first and foremost to Western expectations (Doh, 2009). They do not apply and do not arise here, not least because a Western view has not been assumed. We hope, therefore, that this collection of work can offer some insights into examples of the current developments and issues in counseling and guidance and some of the work it comprises in a specifically African context.

Evans et al. (2000), Connell et al. (2007) paper presents, on the one hand, data that contribute to the establishment of norms for the widely used core outcomes in routine evaluation measure among South African university students and on the other hand supports the validity and reliability of the measure for that population. The position, however, is nuanced in ways that have rarely been reported elsewhere. The distinctive history of South Africa may, it is suggested, have created a lingering legacy of inequality in mental health experienced by black university students in comparison with their white counterparts.

\subsection{Effectiveness of Counseling}

The use of counseling as a way of responding to people in distress has grown rapidly in recent years. While it has proven popular with many people, the rapid growth of counseling has also generated some disquiet and numerous questions (Feltham, 1999). Confusion abounds in many quarters about what counseling is and to what extent it works. The position is complicated by the fact that there is considerable debate about how the effects of counseling should be measured. Nevertheless, robust and consistent evidence about the effectiveness of counseling is now accumulating.

Early medical studies investigating the effectiveness of counseling were hampered by serious confusion about counselors and counseling (Mellor-Clark, 2000). The counseling tested often failed to meet the standards established by the professional bodies for counseling. For example, in some studies, it was assumed that doctors or nurses could 
deliver "counseling" without any dedicated training in counseling. The results of such studies were, obviously, unreliable and unhelpful.

\section{Methodology of the Study}

In this chapter description of the study area, research design, sample size and sampling techniques, tools of data collection, the procedure of data collection, data analysis and reporting and ethical considerations will be proposed.

\subsection{Description of the Study Area}

Jimma town is located in Oromia National Regional State, in Jimma zone, Jimma Wereda at a distance of 325 Kms from Addis Ababa. Jimma town was founded in 1837and is the largest city in the Oromia region, southwestern Ethiopia. Jimma is one of the reform towns in the region and has a city administration, municipality and has13 kebele's (Central Statistical Agency, 2007). And based on figures from the Central Statistical Agency (CSA) in 2007, this town has an estimated total population of 159,009 of whom 80,897 are males and 78,112 are females. And Jimma University Teaching Hospital (JUTH) is located here.

The other study area is Amanuel Mental Health Specialized Hospital which located in Addis Ababa, the largest and capital city of Ethiopia, and it has the status of both a city and a state. As of the latest 2007 population census conducted by the Ethiopian national statistics authorities, Addis Ababa has a total population of 2,739,551 urban and rural inhabitants. For the capital city, 662,728 households were counted living in 628,984 housing units, which results in an average of 5.3 persons to a household. The hospital provides extensive outpatient and a limited inpatient treatment service with 361 beds, mostly dedicated to treatment. Currently, there are eleven (11) wards namely psychotic ward (with five case teams), mood ward (with 3 case teams), substance abuse ward, emergency ward, and Forensic ward.

\subsection{Sample Size and Sampling Techniques \\ 3.2.1. Sample Size}

The study populations were patients' who are admitted to Amanuel Mental Health Specialized Hospital and Jimma University Teaching Hospital (psychiatry clinic) which have an estimated population of 350 . By using the standard formula of sampling, about 123 participants were selected for the study in systematic sampling techniques. In addition, two (2) individuals specifically the head department of both institutions were selected purposively for interview.

\subsubsection{Sampling Techniques}

The study was employed as a probability sampling system. The purpose of using systematic sampling techniques is to make sample bias free, representative, and easy to administer. But, patients with severe problems and who cannot express themselves were excluded from this study.

\subsubsection{Tools of Data Collection}

Structured interviews, observation, and questionnaires were used to collect relevant data for research from participants. A structured interview was compiled to gather socio-demographic information of participants and to assess counseling practice. Observation in this study was focused on the availability of counseling rooms, trained counselor and documentation systems of counseling sessions in the institutions.

Two quantitative questionnaires were used to gather quantitative data. Quantitative measures were adapted through trial measures and translated from English to Amharic and Afan Oromo.

\subsection{Procedure Data Collection}

In the data gathering procedure, before any action takes place, items of tools of data collection such as rating scale questionnaire and interview guide questions were developed in the English language and translated to Amharic and Afan Oromo language. Afterward, these items were checked whether or not it is worth to measure the point it intended to deal with.

\subsection{Method of Data Analysis}

Data will be analyzed both quantitatively and qualitatively. Quantitative data obtained through questionnaires will be analyzed using SPSS version 21 software. To minimize decision error, the study will use 0.05 levels of significances. The effectiveness of counseling to treat mental illness will be analyzed using inferential statistics independent t-test and the difference of different types of mental illness will be analyzed by ANOVA, depending on the number of groups in the study and comparison between the two institutions will be analyzed by Mann Whitney independent t-test. In addition, trends and perceptions toward counseling among mental health professionals will be analyzed by descriptive statistics.

\section{Results and Discussions}

There were 123 patients who participated in the study. Table 1, presents the descriptive data related to the sociodemographic characteristics of patients. 
Table-1. Socio-Demographic Characteristics

\begin{tabular}{|c|c|c|c|c|}
\hline Characteristics & & Frequency & Percentage & Remark \\
\hline \multirow[t]{2}{*}{ Gender } & Male & 73 & 59.35 & \\
\hline & Female & 50 & 40.65 & \\
\hline \multirow[t]{6}{*}{ Age } & $10-19$ & 15 & 12.2 & \\
\hline & $20-29$ & 49 & 39.8 & \\
\hline & $30-39$ & 43 & 34.9 & \\
\hline & $40-49$ & 16 & 13.1 & \\
\hline & $50+$ & 0 & 0 & \\
\hline & Rural & 41 & 33.4 & \\
\hline \multirow[t]{5}{*}{ Admitted for } & First time & 20 & 16.26 & \\
\hline & Second time & 39 & 31.7 & \\
\hline & Third time & 30 & 24.4 & \\
\hline & Fourth time & 17 & 13.82 & \\
\hline & Above & 17 & 13.82 & \\
\hline \multirow[t]{4}{*}{ Diagnosed disorders } & Schizophrenia & 30 & 24.4 & \\
\hline & Major depression & 27 & 21.95 & \\
\hline & Bipolar & 27 & 21.95 & \\
\hline & Substance abuse & 39 & 31.7 & \\
\hline
\end{tabular}

As indicated in table 1 , of the 123 patients participated in the study, more than half $(73,59.35 \%)$ were males and $50(40.65 \%)$ were females. The age of the patients ranged from 10 years to 49 years, with an average age of 30.75 years. One hundred three $(83.74 \%)$ participants were admitted for more than one time and only 20 (16.26) of them for the first time. Also, $80(65 \%)$ of the participants were inpatients and $43(35 \%)$ of them were outpatients. In terms of diagnosed disorders, Schizophrenia accounts 30 (24.4\%), major depression 27 (21.95\%), Bipolar disorder 27 $(21.95 \%)$ and substance abuse $39(31.7 \%)$ of participants.

\subsection{Counseling Practice}

The following table reveals the frequency and percentage distribution of the counseling practice of JUTH and AMHSH.

The information reveals that the majorities $30,(88.2 \%)$ of the patients are from JUTH and only $15,(16.85 \%)$ of the patients from AMHSH did not gain counseling services. In reverse 74, (83.15\%) of the patients from AMHSH and $4,(11.8 \%)$ of the patients from JUSH get counseling service.

\subsection{Effectiveness of Counseling}

This indicates that the availability of counseling services in JUTH is very uncommon and the result of the positive outcome of patients in this institution was comparatively low which shows that the counseling service of the institution is ineffective. The clinic is dependent on the medication part of the patients' treatment. Consequently, AMHSH gives attention to counseling and positive outcome of counseling service which was effective. Cohen's effect size estimates $r=0.325$, indicates that there is a moderate effect in the provisions of counseling in the institutions.

\subsection{Effectiveness of Counseling Based on Disorders}

To know for which disorder counseling is more effective, a positive outcome rating scale test was analyzed by descriptive statistics and ANOVA. Table 2 shows the descriptive statistics of the test. From the total participants of the study $n=123,78$ of them were selected for they were gain counseling service from the institutions (74) from AMHSH and (4) from JUSH.

Table-2.

\begin{tabular}{l|ll|l|l|l}
\hline Sum of squares & Df & Mean squares & \multicolumn{1}{c}{ F } & \multicolumn{1}{c}{ Sig. } \\
\hline Between groups & 255.136 & 3 & 85.045 & 33.176 & .000 \\
\hline Within groups & 189.697 & 74 & 2.563 & & \\
\cline { 1 - 4 } Total & 444.833 & 77 & & \\
\hline
\end{tabular}

The above table revealed that there is a significant difference between disorders in the value of positive outcome rating scale with $0.000 \mathrm{p}$-values at .05 . Homogeneity of variance for the above ANOVA summary is $\mathrm{p}=0.5$ (Levene Statistic) which is greater than the alpha value of .05 indicating that this assumption underlying the application of ANOVA was meet. The omega square $=0.55$ indicated that $55 \%$ of the variation in the test score is attributable to the difference between the four groups of disorders.

The graph below makes clear of the above results showing the difference between the positive outcome rating scale values. 
Figure-1. Means plot of positive outcome and disorders

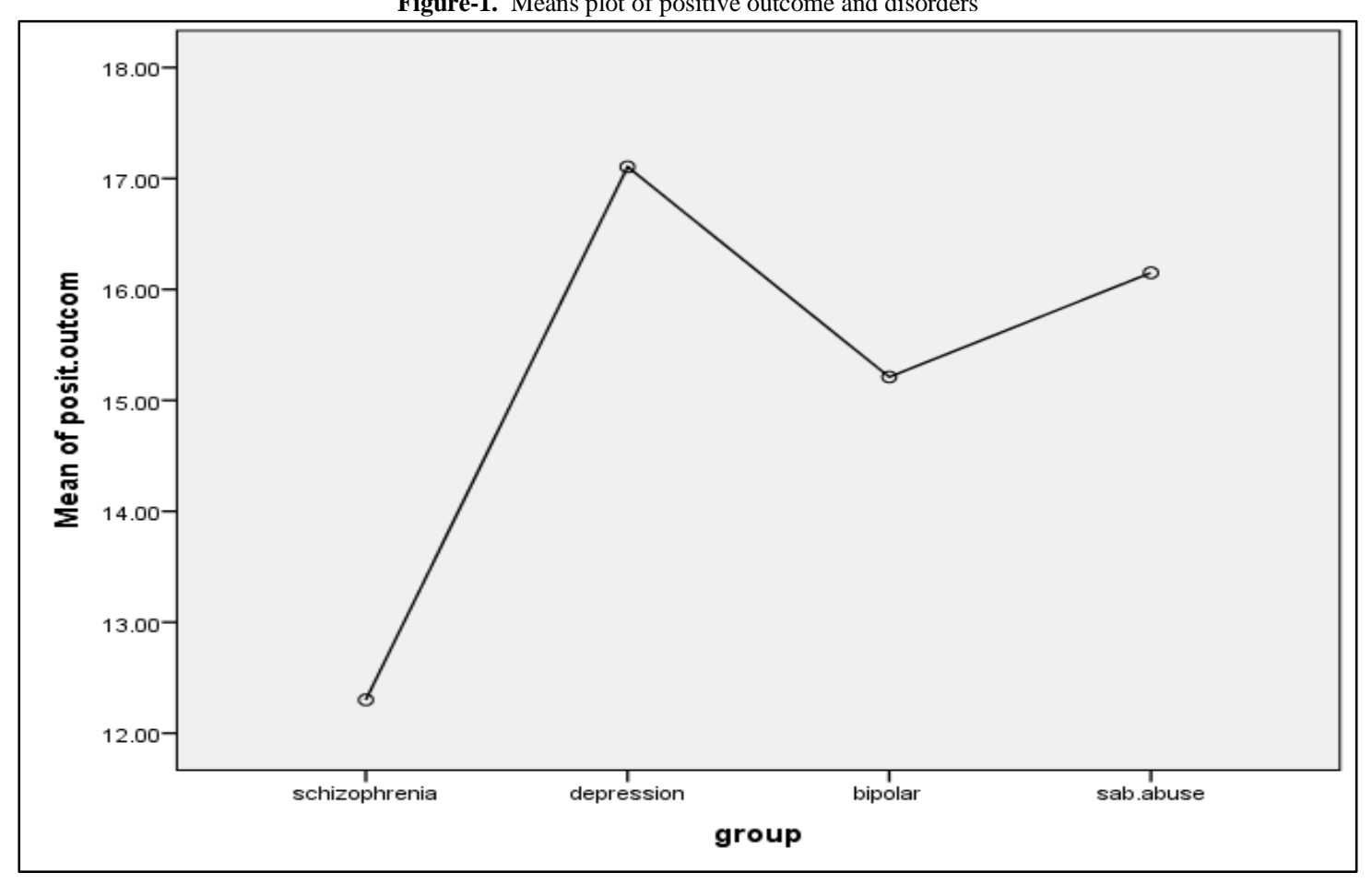

The above figure shows that counseling was so effective in treating depression and substance abuse with a mean score of 17 and 16.15 respectively.

\subsection{Qualitative Analysis of the Practice of Counseling}

Qualitative analysis was employed in this study to fill the questions like the availability of separated counseling rooms, trained counselors and recorded documents of the sessions. These things are very important to provide effective counseling for clients.

\subsubsection{Observation Result}

From the observation, there is no separated room for the counseling service in JUSH, one trained counselor and two clinical psychologists are there to discuss the nature of the disorders with clients. There is no documented record of patients for counseling session of the client. On the other hand, AMHSH has eleven (11) wards, (four (4) for female and seven (7) for male patients). These wards have their own room for counseling. Two (2) trained counselors are there and nine (9) general psychologists placed on the lash of the wards. This means one (1) general psychologist is for every ward and supervised by counselors. But, there is no written document for the counseling sessions conducted in the hospital.

\subsubsection{Interview Result}

Counseling deals with wellness, personal growth, career, education, and empowerment concerns. In other words, counselors work in areas that involve a glut of issues including personal, interpersonal and social issues of the peoples. I this study two (2) head of the institutions was involved.

In the provision of counseling service, the head JUSH; (psychiatric clinic) said that: "As much as possible we are giving counseling service for our patients. But, for there are a lot of patients in the hospital (psychiatric clinic) it is difficult to address the entire." 3:21 pm 90/05/2018

The head continued stating the uses of counseling for patients: "I think counseling is very useful for our patients to rehabilitate from their illness. But, we do not have any separated room for counseling as well as trained counselors. We are working with two clinical psychologists and one other counseling psychologist." But unavailability of the room is challenging issues.

According to the speech of the head, there are other challenges that limit them from giving organized counseling services. "Lack of budget is our major problem to recruit counselors. In a psychiatric clinic, we have only one building with limited rooms.

So, it is difficult to have a separate counseling room. Even the rooms are not enough for patients to make a comfortable place. But, we had reported about the problem for the concerned body and expect that the problem will be eliminated in the near future."

The head of AMHSH was answered the following for the question. In the provision of counseling service the head of the clinic said: "We provide counseling service for all of our patients. Because we believe that counseling is very important to support medication treatment and increase awareness of their disorder. So, all inpatients gain three (3) counseling sessions per week. Our treatment teams include counselors, psychologists, and clinical psychologists. The team has its own room to perform their daily activities." 4:00 am 10/05/2018. 
The institution has its own challenges that are facing. The head continued stating that: "As the hospital, the ward numbers are not enough to serve huge numbers of in need peoples. The capacity of the hospital is not equivalent to the need of society. Also, an insufficient salary of the employer is causing professionals to turn over. Our dread in the future is the loss of these professionals."

\section{Discussion}

Both institutions are delivering counseling service differently which mean AMHSH is mostly focused on counseling and JUTH gives little attention to counseling service. For this reason, the positive outcome rating scale of JUSH was low which is conversely seen as the high score value of positive outcome rating scale of patients in AMHSH that the attention they give for counseling in treating mentally ill peoples.

This result is also supported by qualitative results of observation and interview with both heads of the institutions in JUSH psychiatric clinic where there is no separated room for counseling service and only one trained counselors. This shows that the counseling service in this institution is atypical and some sort of the clients' problem is discussed by the general psychologist as guidance than counseling. In AMHSH the result is reverse. In this institution, treatment of drug and counseling is provided in parallel. So, this leads the patients of this institution to effectively cope with their illness as shown by a positive outcome rating scale. Also, a trend of counseling is characterized by the regularity of the session by which the institution is taking action. As presented in the last chapter, the patients of this institution gain three counseling sessions per week. These have their own contribution to the positive outcome of the clients in the institution.

The finding of this research also showed that there is a difference between the disorders in positive outcomes. Depending on the result, depression is the disorder that effectively managed by counseling.

Substance abuse is the other disorder that gives the best response to counseling. Patients' of this disorder gain benefit from counseling services according to this study.

In this study, Bipolar disorder and schizophrenia were not given as such result in a positive outcome in comparison with depression and substance abuse.

In general, when depression and substance abuse are mostly managed by counseling, bipolar and schizophrenia were not as such brought positive outcomes by counseling.

\section{Conclusion}

The objectives of this study were to investigate counseling trends or practice of two mental health institutions and their difference in the provision of counseling services. Accordingly, assessing the effectiveness of the service and how mental health professional perceive the uses of counseling for the treatment of psychological disorders were other objectives of the study.

From the above finding, it is possible to conclude that counseling service did not gain attention and considered as ignored part of treatment in JUSH. But, the high level of motivation to provide counseling in AMHSH should be taken as a good move to expand counseling services all over the country. For the problem like depression and substance abuse, using counseling as much as possible may help the clients to cope and overcome their problem within a short period of time and ineffective way. Because peoples are not interested to take drugs for a long period of time and them drop-out the pharmaceutical treatment after a time. This leads them to the relapse of the problem after a given time.

Counseling effect is more last longer and helps people to improve their problem by themselves. For the problem like schizophrenia and bipolar disorders, the positive outcome of counseling is not significant. But, this is not saying that counseling is not important for these disorders. Counseling helps these peoples by enhancing medication adherence, diminishing clinical symptoms, and enhancing the quality of life and social adjustment. Adjunctive counseling for the treatment of bipolar and schizophrenia appears to have strong benefits in reducing relapses, alleviating depression, and improving general interpersonal and health functioning without adding an additional cost burden.

\section{Recommendation}

Based on the findings and conclusion from the study, the following recommendations are made.

Psychological disorders have a variety of psychological and medical roots and treatment of these problems should also recognize both aspects of treatment. So, by understanding the use of counseling, JUTH has to incorporate counseling service in the treatment part to increase the wellness of patients. Generally, introducing counseling interventions in this hospital is needs more attention. For, ignoring psychological treatment loosens to effectively helping the client. In terms of AMHSH, increasing the capacity of the hospitals to address numbers of patients has needed.

For the disorders such as depression and substance abuse, increasing psychological treatment is more effective to minimize the burden of the limited number of psychiatrists in the hospitals. So, both institutions have to implement more counseling than medication for these disorders. As much as possible, extending the strategy by which treatment of mental illness begun from a counselor is useful to prevent time and resource of both institutions. This intern helps to save time and energy from other professionals in the institutions.

\section{References}

America Psychological Association (2013). Counseling Psychology. Available: https://www.apa.org 
Becker, A. E. and Kleinman, A. (2013). Mental health and the global agenda. New England Journal of Medicine, 369(1): 66-73.

Berhanu, N. and Solomon, S. (2014). Trends and possible causes of mental illness. European Scientific Journal, 10(29): Available: https://eujournal.org/index.php/esj/article/view/4433

Central Statistical Agency (2007). Jimma. https://en.wikipedia.org/wiki/Central_Statistical_Agency

Collins, P. Y., Patel, V., Joestl, S. S., March, D., Insel, T. R. and Daar, A. S. (2011). Grand challenges in global mental health: A consortium of researchers, advocates and clinicians announce share research priorities for improving the lives of people with mental illness around the world, and calls for urgent action and investment. Nature, 475(7354): 27-30.

Connell, J., Michael, B. and Maller-Clark (2007). Mental health norms of students attending counseing services benchmarked against an age matched primary care sample. British Journal of Guidance and Counseling, 35(1): 41-57.

Doh, E. F. (2009). Stereotyping Africa: Surprising answers to surprising questions. Langaa RPCIG.

Evans, C., Mellor-Clark, J., Margison, F., Barkham, M., Audin, K., Connell, J. and McGrath, G. (2000). Clinical outcomes in routine evaluation. Journal of Mental Health, 9(3): 247-55.

Feltham, C. (1999). Controversies in psychotherapy and counselling sage. London.

Mellor-Clark, J. (2000). Counselling in rimary care. Brotish association of counseling and psychotherapy. Rugby publishing.

Okasha, A. (2002). Mental health in africa: The role of the world psychological association. World Psychiatry, 1(1): $32-35$. 